\title{
Individual Case Study: Improved Memory Functioning following Neurocognitive Training in a Diagnosed TBI patient
}

\section{Barbara C Fisher ${ }^{*}$ and Danielle Szokola}

United Psychological Services, 47818 Van Dyke, Shelby Charter Township, MI 48317, USA

*Corresponding author: Barbara C Fisher, Licensed Psychologist/Neuropsychologist, Board Certified Behavioral Sleep Medicine, Clinic Director, United Psychological Services, 47818 Van Dyke, Shelby Charter Township, MI 48317, USA, Tel: 586-323-3620; Fax: 586-323-3568; E-mail: drbcfisher@hotmail.com

Received date: February 13, 2017; Accepted date: March 24, 2017; Published date: March 31, 2017

Copyright: () 2017 Fisher BC, et al. This is an open-access article distributed under the terms of the Creative Commons Attribution License, which permits unrestricted use, distribution, and reproduction in any medium, provided the original author and source are credited.

\section{Introduction}

Patients have been receiving neurocognitive training as part of their treatment at an outpatient mental health facility for the past ten years and findings are the result of an ongoing study completed over the past five years. The program consists of neuropsychological assessment, which is patient specific and related to the reason for evaluation. Based upon the individual neuropsychological evaluation, a specific treatment plan is created. The plan is patient specific. Evaluation is completed, using the same testing at the same time of day, following a general range of three to six months of treatment to ascertain changes and efficacy of the program.

Neurocognitive intervention has been gaining credence in recent research, along with the modifiable risk factors and exercise as an intervention to address dementia decline. There are commercial programs that have shown to have efficacy and large scale studies have been conducted revealing the benefit of cognitive training and stimulation [1,2]. Cognitive training intervention and cognitive enhancement have been found to have positive effects, as well as impacting cognitive decline in the aged population [3,4]. When cognitive training was compared to physical training, improvement was distinct revealing improved executive function with cognitive training and improved memory with physical training [5]. Only modest support was shown for the potential of videogame training to improve cognitive function in healthy older adults and another study revealed only specific effects [6]. The transfer of training to real life improvement was seen as offering mixed results [7-9]. Finally, another study revealed that an active lifestyle was more effective than the effect of short term training interventions as impacting cognitive change over time in a dementia risk group.

This is the case study of a 60 year old man was involved in a motor vehicle accident resulting in a brief loss of consciousness and diagnosis of traumatic brain injury by neuropsychological evaluation. He was in perfect health prior to the injury. Testing was completed over six month's post injury suggesting that this was past the well-known amount of time for spontaneous recovery. Therapy began eight month's post-injury. The man is from another country and an interpreter was present for all of the treatment sessions. He was provided with neurocognitive training twice per week for one hour per session for a period of seven months and re-evaluated on selected memory testing with the same examiner at the same time of day.

Based upon initial neuropsychological evaluation, a plan is completed to address specific neurocognitive difficulties and in this case, memory was agreed upon as the first area of brain function to treat. The plan is patient specific and developed based upon the results of neuropsychological evaluation. In this case, therapy targeted areas of memory (short term, learning, delayed recall, recognition) as well as the impact of executive reasoning deficits of sequential processing, integration and selective attention. There are over 200 games and activities to choose from; ranging from items that have been created as well as published games being used to address the specific deficits. $\mathrm{He}$ was seen twice per week for one hour each visit and he was given a carryover program for the home setting. Therapy begins with the use of specific games and activities designed to address these issues. The activities either increase in difficulty and/or there are additions of variables such as speed. This is an ongoing program, continually changed and altered by the therapist who is observing in the session the response of the patient.

Re-evaluation was completed with visual memory measures and an assessment used to track dementia through time, the Repeatable Battery for the Assessment of Neuropsychological Status (RBANS). The verbal portions of this measure were translated into his own language. He was administered the visual memory tests from the following memory batteries; Memory Assessment System (MAS), Doors and People Test, Wide Range Assessment of Memory and Learning (WRAML-2) and Brief Visuospatial Memory Test-Revised (BVMT-R). Scoring is based upon age and normative data for each test. Results revealed significant improvement in memory functioning seven months from the beginning of treatment. He improved on every index, excluding two indices and one visual memory measure; there was a decline in delayed recall of a short story from the RBANS and on the visual recognition task from the Doors and People Test (performance declined from below average to well below average limits). He declined on the last version of the BVMT-R, it was initially administered twice, without and then with glasses. Glasses were not a variable for the remainder of the tests reported here that were readministered.

Re-assessment on the RBANS resulted in a significantly improved overall score from well below average to the average range. He improved significantly on tasks of immediate memory from highly impaired to well below average limits. Delayed memory improved from well below average to the average range. Visuospatial/ constructional processing improved from superior to very superior limits, suggesting likely rather high cognitive reserve seen elsewhere in this re-evaluation. Language improved from highly impaired limits to the below average range and attention improved slightly from low average to average limits.

Scaled scoring on the dementia assessment revealed significant improvement in the learning of a discrete list of words, delayed recall was similar although improved. Delayed recognition of the words (from distracter items) was significantly improved from impaired limits to a perfect score in the average range which contributed to his improved delayed recall index score. Learning of the short story improved only slightly for learning and declined from low average to 
Page 2 of 4

below average for delayed recall. Visual recall improved from below average to average limits. Naming of common items improved from impaired limits to the average range, while word retrieval remained within well below average limits. Short term recall of numbers remained within superior limits, while the speeded coding task improved slightly, although remaining within well below average limits.

He was re-assessed on a number of visual memory tests to address his progress in treatment. He improved on a measure of visual retrieval measure for five designs (presented one at a time) on the WRAML-2 from below average to high average limits. Another measure of visual retrieval (MAS) improved from average to above average limits for a total of two designs (presented one at a time). A task of immediate visual recognition for designs (MAS) improved from average to high average and delayed recognition improved from average to very superior limits. A short term visual task (MAS) dependent upon sequential processing improved from well below average to average limits.

A visual learning task (Doors and People Test) improved from average to above average limits and a perfect score in the recall of four shapes. Delayed recall of the shapes improved from below average to average limits, he only missed one detail. He continues to have more difficulty with the increased amount of visual stimuli which may be suggestive of the impact of executive reasoning (seen on prior assessment) and/or memory overload. On a visual learning task (BVMT-R) involving the learning and recall of six designs, his overall total recall score was declined from above average to the average range. Learning was improved from average to above average limits and delayed recall declined from high average to average limits. He struggled with the details of the designs (as well as the position on the page) and performance declined from the last learning trial to the delayed recall trial.

Re-assessment revealed the most robust improvement on memory evaluation for the visual memory measures. He improved significantly on a task of recalling discrete words and declined for the delayed story recall. He continues to struggle with word retrieval seen on the RBANS. The pattern of the test results suggests ongoing greater difficulty when overwhelmed by too much stimuli presented at one time. This may be the result of executive reasoning processes which were not assessed in this evaluation. Results point to improvement that is significant from the intervention of neurocognitive training received two times per week. As a result of re-evaluation, the focus of neurocognitive intervention/training will shift to executive reasoning, as well as attention and re-evaluation will be completed in three months' time. He reports that he feels that he can rely more upon his memory for daily life tasks. This case study is commensurate with ongoing research and improvement seen over the course of the last ten years, shown in abstracts presented at area conferences since 2012 by this facility [10-18].

\section{Limitations}

While it is well-known and documented that six months' time is the period of spontaneous recovery from a brain injury, this does not totally rule out the impact of time upon the natural process of recovery. From a clinical perspective, the recovery process is greatest within the first six months of injury and declines after that time and would not reveal the robust effect that has been seen with the introduction of neurocognitive training.

\section{Specific Test Findings}

Scaled Scores: Average $=10$, Standard Deviation $=3$. This means that a score of 13 would be above average and a score of 7 would be below average. Standard Scores, IQ Quotient or Quotient Scores: Average $=100$, Standard Deviation $=15$. This means that a score of 115 would be above average and a score of 85 would be below average.

\section{Dementia Assessment}

\section{Index scores on the RBANS}

Index scores are based upon standard scoring whereby 100 is average and 15 is the standard deviation, meaning that 85 would be below average and 115 above average. Normative data based upon age (Tables 1a-1d).

\begin{tabular}{|l|c|c|c|c|c|c|}
\hline Index & $\begin{array}{c}\text { Immediate } \\
\text { Memory }\end{array}$ & $\begin{array}{c}\text { Visuospatial } \\
\text { Visuoconstructional }\end{array}$ & Language & Attention & $\begin{array}{c}\text { Delayed } \\
\text { Memory }\end{array}$ & $\begin{array}{c}\text { Total } \\
\text { Scale }\end{array}$ \\
\hline SS & 53 & 121 & 57 & 91 & 71 & 73 \\
\hline \%tile & $0.10 \%$ & $92 \%$ & $0.20 \%$ & $27 \%$ & $3 \%$ & $4 \%$ \\
\hline
\end{tabular}

Table 1a: Normative data: April 2016.

\begin{tabular}{|l|c|c|c|c|c|c|}
\hline Index & $\begin{array}{c}\text { Immediate } \\
\text { Memory }\end{array}$ & $\begin{array}{c}\text { Visuospatial } \\
\text { Visuoconstructional }\end{array}$ & Language & Attention & $\begin{array}{c}\text { Delayed } \\
\text { Memory }\end{array}$ & $\begin{array}{c}\text { Total } \\
\text { Scale }\end{array}$ \\
\hline SS & 78 & 131 & 94 & 94 & 100 & 95 \\
\hline$\%$ tile & $7 \%$ & $98 \%$ & $34 \%$ & $34 \%$ & $50 \%$ & $37 \%$ \\
\hline
\end{tabular}

Table 1b: Normative data: January 2017.

\begin{tabular}{|l|c|c|}
\hline Subtest & Scaled Score & Percentile \\
\hline List Learning & 2 & \\
\hline Story Memory & 14 & \\
\hline Figure Copy & & 51-75\%tile \\
\hline Line Orientation & 3 & Below 2nd \%tile \\
\hline Picture Naming & 15 & \\
\hline Semantic Fluency & 2 & Below 2nd \%tile \\
\hline Digit Span & & \\
\hline Coding & & \\
\hline List Recall & & \\
\hline List Recognition & & \\
\hline Story Recall & & \\
\hline Figure Recall & & \\
\hline
\end{tabular}

Table 1c: April 2016 specific subtest scores. 
Citation: Fisher BC, Szokola D (2017) Individual Case Study: Improved Memory Functioning following Neurocognitive Training in a Diagnosed TBI patient. J Neurol Neurophysiol 8: 416. doi:10.4172/2155-9562.1000416

Page 3 of 4

\begin{tabular}{|l|c|l|}
\hline Subtest & Scaled Score & Percentile \\
\hline List Learning & 8 & \\
\hline Story Memory & 4 & \\
\hline Figure Copy & 14 & \\
\hline Line Orientation & & Above 75\% tile \\
\hline Picture Naming & & $17-25 \%$ tile \\
\hline Semantic Fluency & 3 & \\
\hline Digit Span & 15 & \\
\hline Coding & 3 & \\
\hline List Recall & & $51-75 \%$ tile \\
\hline List Recognition & & $51-75 \%$ tile \\
\hline Story Recall & 5 & \\
\hline Figure Recall & 11 & \\
\hline
\end{tabular}

\section{The doors and people test}

Scores are represented by scaled scores whereby 10 is average and 3 is the standard deviation. Normative data based upon age (Tables 3a and $3 b)$.

\begin{tabular}{|l|l|l|l|}
\hline Doors & 7 & Shapes & 11 \\
\hline
\end{tabular}

Table 3a: Normative data based upon age- April 2016.

\begin{tabular}{|l|l|l|l|}
\hline Doors & 4 & Shapes & 14 \\
\hline
\end{tabular}

Table 3b: Normative data based upon age- January 2017.

The following scores provide further information regarding his performance by comparing the various variables in this memory measure (Tables 4-6).

\begin{tabular}{|l|l|l|l|}
\hline SUBTEST & SS & SUBTEST & SS \\
\hline Visual Memory & 9 & Visual Forgetting & 7 \\
\hline
\end{tabular}

Table 1d: January 2017 specific subtest scores.

\section{Learning and Memory Evaluation}

\section{Brief visuospatial memory test-revised}

Presented in $\mathrm{T}$ score formulations whereby 50 represent the average and 10 is the standard deviation. Normative data based upon age (Tables 2a-2c).

\begin{tabular}{|l|c|c|c|c|c|}
\hline Trial & T score & \%tile & Trial & T score & $\%$ tile \\
\hline Trial 1 & 42 & 21 st & Total Recall & 28 & 1 st \\
\hline Trial 2 & 30 & 2 nd & Delayed Recall & 37 & 10 th \\
\hline Trial 3 & $<20$ & $<1$ st & Learning Score & 35 & 7 th \\
\hline
\end{tabular}

Table 2a: Normative data based upon age- April 2016.

\begin{tabular}{|l|c|c|c|c|c|}
\hline Trial & T score & \%tile & Trial & T score & \%tile \\
\hline Trial 1 & 58 & 79th & Total Recall & 60 & 84th \\
\hline Trial 2 & 60 & 84th & Delayed Recall & 57 & 76th \\
\hline Trial 3 & 60 & 84th & Learning Score & 52 & 58th \\
\hline
\end{tabular}

Table 2b: Normative data based upon age- May 2016.

\begin{tabular}{|l|c|c|l|l|l|}
\hline Trial & T score & \%tile & Trial & T score & \%tile \\
\hline Trial 1 & 43 & 24 th & Total Recall & 47 & 38 th \\
\hline Trial 2 & 45 & 31 st & Delayed Recall & 47 & 38 th \\
\hline Trial 3 & 55 & 69 th & Learning Score & 63 & 90th \\
\hline
\end{tabular}

Table 4a: April 2016.

\begin{tabular}{|l|l|l|l|}
\hline SUBTEST & SS & SUBTEST & SS \\
\hline Visual Memory & 9 & Visual Forgetting & 9 \\
\hline
\end{tabular}

Table 4b: January 2017.

\section{The memory assessment system (MAS)}

\begin{tabular}{|l|l|}
\hline Index Score & Visual Memory \\
\hline May 2016 Standard Score & $99(47$ th \%tile) \\
\hline January 2017 Standard Score & $120(91$ st \%tile) \\
\hline
\end{tabular}

Table 5a: Normative data based upon age, 100 is average and 15 is the standard deviation.

\begin{tabular}{|l|l|l|l|}
\hline SUBTEST & SS & SUBTEST & SS \\
\hline Visual Span & 4 & Visual Reproduction & 9 \\
\hline Delayed Visual Recognition & 9 & Immediate Visual Recognition & 10 \\
\hline
\end{tabular}

Table 5b: May 2016 Scaled scored.

\begin{tabular}{|l|l|l|l|}
\hline \multicolumn{1}{|c|}{ SUBTEST } & SS & SUBTEST & SS \\
\hline Visual Span & 9 & Visual Reproduction & 12 \\
\hline Delayed Visual Recognition & 14 & Immediate Visual Recognition & 17 \\
\hline
\end{tabular}

Table 5c: January 2017 Scaled scored.

Table 2c: Normative data based upon age- January 2017. 
Citation: Fisher BC, Szokola D (2017) Individual Case Study: Improved Memory Functioning following Neurocognitive Training in a Diagnosed TBI patient. J Neurol Neurophysiol 8: 416. doi:10.4172/2155-9562.1000416

Page 4 of 4

Wide range assessment of memory and learning (WRAML 2)

\begin{tabular}{|l|l|l|}
\hline Date Tested & Index & SS \\
\hline May 2016 & Design Memory & 5 \\
\hline January 2017 & Design Memory & 12 \\
\hline
\end{tabular}

Table 6: Scaled score based upon age.

\section{References}

1. Shah TM, Weinborn M, Verdile G, Sohrabi HR, Martins RN (2017) Enhancing cognitive functioning in healthy older adults; a systemic review of the clinical significance of commercially available computerized cognitive training in preventing cognitive decline. Neuropsychol Rev 27: 62-80.

2. Moruzzi (2017) Randomized trial on the effects of a combined physical/ cognitive training in aged MCI subjects: The train the brain study. Sci Rep 7: 39471 .

3. Ngandu T, Lehtisalo J, Solomon A, Levälahti E, Ahtiluoto S, et al. (2015) A 2 year multidomain intervention of diet, exercise, cognitive training, and vascular risk monitoring versus control to prevent cognitive decline in at risk elderly people (FINGER) a randomized controlled trial. Lancet 385: 2255-2263.

4. Valenzuela M, Sachdev P (2009) Can cognitive exercise prevent the onset of dementia? Systematic review of randomized clinical trials with longitudinal follow-up. Am J Geriatr Psychiatry 17: 179-187.

5. Küster OC, Fissler P, Laptinskaya D, Thurm F, Scharpf A, et al. (2016) Cognitive change is more positively associated with an active lifestyle than with training interventions in older adults at risk for dementia, a controlled intervention clinical trial. BMC Psychiatry 16: 315.

6. Chapman SB, Aslan S, Spence JS, Keebler MW, DeFina LF, et al. (2016) Distinct brain and behavioral benefits from cognitive vs. physical training: A randomized trial in aging adults. Front Hum Neurosci 10: 338.

7. van Muijden J, Band GPH, Hommel B (2012) Online games training aging brains; limited transfer to cognitive control functions. Front Hum Neurosci 6: 221 .

8. Ballesteros S, Prieto A, Mayas J, Toril P, Pita C, et al. (2014) Brain training with non-action video games enhances aspects of cognition in older adults, a randomized controlled trial. Front Aging Neurosci 6: 277.
9. Baniqued PL, Kranz MB, Voss MW, Lee H, Cosman JD, et al. (2013) Cognitive training with casual video games; points to consider. Front Psychol 4: 1010.

10. Fisher BC, Garges DM (2016) Cognitive training therapeutic program for memory/neuropsychological deficits, on-going research in dementia population, American Alzheimer's Association International Conference, Toronto, Canada.

11. Fisher BC, Garges DM (2015) Efficacy of a therapeutic program for memory/neuropsychological deficits, American Neurological Association 140th Annual Meeting, Chicago, Il, USA.

12. Fisher BC, Garges DM (2015) On-going re-evaluation of memory deficits in diagnosed dementia population while undergoing and following cognitive therapy/training, American Alzheimer's Association International Conference, Washington, DC

13. Fisher BC (2014) The benefits of cognitive stimulation or training/ rehabilitation upon brain function as an efficacious treatment for diagnosed dementia or mild cognitive decline. J Alzheimers Dis Parkinsonism 4: 161.

14. Fisher BC (2014) The future of dementia we can make a difference: pairing cognitive training with specific neurocognitive testing to improve memory function. 2nd International Conference on Alzheimers disease and Dementia, OMICS Group, Valencia, Spain.

15. Fisher BC, Garges DM (2014) Evaluation of the remediation of neuropsychological deficits in diagnosed dementia population through cognitive therapy/training, poster presentation, 2nd International Conference on Alzheimers Disease and Dementia, OMICS Group, Valencia, Spain.

16. Fisher BC, Garges DM (2013) Analysis of the efficacy of a therapeutic cognitive training therapeutic program for memory/neuropsychological deficits for dementia population, poster presentation, Alzheimer's Association International Conference, Boston, MA.

17. Fisher BC, Garges DM (2013) Analysis of the efficacy of a therapeutic cognitive training therapeutic program for memory/neuropsychological deficits for dementia population, Poster Presentation, July 2013, Alzheimer's Association International Conference, Boston, MA

18. Fisher BC, Garges DM (2012) Efficacy of a brain/cognitive training therapeutic program for diagnosed dementia, poster presentation, American Neuropsychological Association 137th Annual Meeting, Boston, MA. 